\title{
Educação popular: um projeto coletivo dos movimentos sociais populares
}

\author{
Marlene Ribeiro*
}

\section{Resumo:}

O artigo trata da educação popular referida à educação do campo. Visa a explicitar a educação projetada pelos sujeitos políticos coletivos dos movimentos sociais populares em contraposição ao modelo civilizatório de escola moderna, bem como desvelar o movimento contraditório que impregna os conceitos e as experiências das organizações populares como sujeitos da educação popular. A educação moderna produzida pela burguesia está teduzida aos processos escolares, negando os aprendizados da experiência, da cultura e do trabalho. Do mesmo modo que o trabalho é princípio educativo, o movimento social popular é educador como formador da classe e de uma identidade de classe. A educação popular tem, assim, um caráter de classe, e é isso o que a distingue do conceito abstrato de educação moderna. A crítica à educação reduzida à escola não significa negar a instituição escolar ou deixar de reconhecer o direito das classes populares à educação, que é universal. A finalidade a que nos propomos é levantar elementos para construir a concepção de educação popular resgatando sua relação com o mundo do trabaIho, no qual se constituem os movimentos sociais populares que, nas suas práticas sociais e pedagógicas, a definem.

Palavras-chave: Educação Popular. Movimentos Sociais e Educação. Trabalho e Educação.

\footnotetext{
* Professora Titular do Departamento de Estudos Básicos e Programa de Pós-Graduação em Educação da Faculdade de Educação da Universidade Federal do Rio Grande do Sul. Pós-Doutorado em Políticas Públicas de Formação Humana da Universidade do Estado do Rio de Janeiro. Bolsista de produtividade do CNPq; Participação no Convênio CAPES/ GRICES - Brasil e Portugal - 2008.
} 
A reflexão proposta neste artigo decorre de estudos relacionados ao projeto "Experiências pedagógicas dos movimentos sociais populares e políticas de educação rural/do campo: confronto de concepções", com apoio do CNPq. Nesses estudos, identificamos como educação popular a educação do campo, que vem sendo construída pelos movimentos sociais populares rurais/do campo. Nosso propósito é contrapor o modelo civilizatório de escola rural, urbanocêntrica, historicamente oferecida aos trabalhadores e trabalhadoras que vivem nas áreas rurais, à educação do campo desenhada e posta em prática pelos sujeitos-político-coletivos, movimentos-sociopopulares. A crítica que fazemos à escola, por reduzir a educação à instrução e por estar separada do mundo do trabalho, negando os aprendizados das experiências relacionadas a este trabalho e à cultura, não significa negar a escola ou subestimar a sua importância como um direito conquistado pelas classes populares. Assim, o que pretendemos é mergulhar, no movimento contraditório de aceitar/negar a escola rural/ do campo, nas experiências de educação popular realizadas e nos conceitos formulados pelas organizações populares. Com isso, pensamos obter conhecimentos que nos permitam a compreensão do que os movimentos sociais populares rurais/do campo concebem e colocam em prática como educação popular, aclarando a sua relação com o mundo do trabalho, em que se constituem os sujeitos políticos coletivos - os movimentos sociais populares que a constroem.

Do mesmo modo que a expressão "campo" remete às lutas históricas do campesinato, educação popular carrega o sentido das organizações populares do campo e da cidade que, na sua caminhada histórica, participam, realizam e sistematizam experiências de educação popular. Estão compreendidas nessas experiências, entre outras, a criação do Método Paulo Freire de alfabetização (FREIRE, 1979; PALUDO, 2001) e a educação do campo (ARROYO; CALDAR'T; MOLINA, 2004), em que os movimentos camponeses desempenham papel central.

Tendo por sujeitos coletivos os movimentos sociais populares, a educação do campo que reivindicam e os experimentos pedagógicos que realizam não poderiam, no nosso entendimento, ser identificados senão como educação popular. Todavia, cada um destes termos - educação e popular -, que se unem para definir uma determinada modalidade educativa dirigida ou efetuada por uma determinada população, é carregado de 
sentidos contraditórios que expressam a realidade social cortada pelos antagonismos próprios das classes sociais na sociedade capitalista. Por essa razão, há necessidade de torná-los mais claros, sem, com isso, pretender esgotar a sua compreensão, em particular, nas experiências pedagógicas dos movimentos sociais populares do campo. Tais experiências constituem o objeto do que pretendemos caracterizar como educação popular.

A concepção moderna de educação produzida pela burguesia como a classe vitoriosa na transformação do feudalismo em capitalismo ficou reduzida aos processos escolares, negando ou subordinando os aprendizados da experiência e da cultura, mas, principalmente, os que decorrem do trabalho. Pensamos o trabalho na sua dimensão educativa que, pela relação que o trabalhador estabelece com a natureza, mediada pelas relações consigo mesmo e com os outros trabalhadores, humaniza enquanto produz bens materiais, imateriais, linguagem, arte, conhecimento e cultura. Na relação contraditória que os trabalhadores estabelecem com a classe que se apropria do produto do seu trabalho - porque anteriormente expropriou a terra e os instrumentos de trabalho do camponês e deles se apropriou privadamente -, também há uma dimensão educativa de formação das classes populares que marca as suas construções identificadas como educação popular. Nesse sentido, concordamos com Thompson (1984, p. 38), para quem:

As classes se constituem ao viverem os homens e as mulheres suas relações de produção e ao experimentarem suas situações determinantes dentro do conjunto de relações sociais, com uma cultura e uma expectativa herdadas e ao modelar estas experiências em formas culturais. De modo que, ao final, nenhum modelo pode proporcionar-nos o que deve ser a verdadeira formação da classe em uma determinada etapa do processo. Nenhuma formação de classe propriamente dita da história é mais verdadeira ou mais real do que a outra, e classe se define a si mesma no seu efetivo acontecer.

Essa dimensão educativa, formadora das classes subalternas, pode ser captada no processo histórico de organização dos movimentos sociais populares. Entendemos que as formas através das quais os trabalhadores 
e trabalhadoras se organizam, dando origem aos movimentos sociais populares, como sujeitos políticos coletivos de transformação social e de educação popular, conferem conteúdo a esta realidade histórica e social.

Estas formas, porém, são contraditórias, urna vez que as mesmas se constroem no interior de relações onde se confrontam interesses antagônicos: capital/ trabalho. [...] O processo educativo, iniciado na luta contra a expropriação/proletarização, é marcado pelas práticas contraditórias daqueles que constituem uma consciência de classe na medida em que se organizam, lutam, tefletem, se reorganizam. Alguns voltam atrás. Alguns ficam no meio do caminho. Alguns tomam a dianteira, mas a maioria vai avançando, se disciplinando e reconhecendo como classe. (RIBEIRO, 1987, p. 47-48).

Portanto, o movimento social popular é educador, capaz de forjar uma identidade de classe, conforme é corroborado na obra de Caldart (2000) Escola é mais do que escola, quando analisa a ocupação da escola associada ao processo de construção do MST, que a autora identifica como "um sujeito pedagógico". Por isso, a autora usa a expressão Sem Terra, sem hífen, "[...] sendo as letras maiúsculas indicativas desta condição de nome próprio". Quanto à separação por hífen, "[...] fica como distintivo da relação entre esta identidade coletiva de trabalhadores e trabalhadoras da terra e o Movimento que a transformou em nome próprio e a projeta para além de si mesma" (CALDART, 2000, p. 17).

A educação popular, tal como a compreendemos, tem, então, um caráter de classe, e é isso o que a distingue de um conceito abstrato de educação. Todavia, a definição do que estaria colocado como conceito de sujeito histórico, a partir da experiência de vida e de acompanhamento das lutas sociais, nos tem preocupado, porque nos perguntamos: onde colocar os povos indígenas com suas organizações culturais, suas linguagens, mitos e formas de luta? Nesse sentido é que vimos trabalhando com o conceito gramsciano de classes subalternas, cuja abrangência pode ser um limite, mas também uma solução, pois permite incluir sujeitos sociais que perdem elementos essenciais à sua compreensão quando encerrados na definição de classe operária, nesse caso, "[...] os indios, as mulheres, os negros [...]", 
conforme Ribeiro (1999a, p. 16). Todavia, os limites na concepção de classes subalternas são reconhecidos por seu autor, quando afirma:

Os limites e a força das coisas são restringidos. Por quê? Porque, no fundo, se o subalterno era ontem uma coisa, hoje não mais o é: tornou-se uma pessoa histórica, um protagonista; se ontem era irtesponsável, já que era "paciente" de uma vontade estranha, hoje sente-se responsável, já que não é mais paciente, mas sim agente e necessariamente ativo $\mathrm{e}$ empreendedor. Mas, mesmo ontem, será que ele era apenas simples "paciente", simples "coisa", simples “irresponsabilidade"? Não, por certo; deve-se, aliás, sublinhar que o fatalismo não é senão a maneira pela qual os fracos se revestem de uma vontade ativa $e$ real. (GRAMSCI, 1981, p. 24).

Essa compreensão de subalterno, no nosso entendimento, responde a questões apresentadas por algumas leituras feitas a respeito dos movimentos camponeses, leituras, estas, que não os consideram como capazes de protagonizar transformações sociais, a não ser atrelados aos movimentos operários com os quais eles estiverem associados. Mas pensamos de forma diferente. Por essa razão, mais proximamente, substituímos a expressão gramsciana "classes subalternas", que incorpora uma idéia de posição inferior em uma hierarquia, pela expressão "classes populares", mais rica e consoante com o lugar de sujeito político coletivo que the cabe no confronto de classes.

Se nos referirmos aos movimentos sociais populares do campo e às experiências pedagógicas que vêm realizando, que identificamos como educação populat, separando-os das formas como se organizam e lutam pela terra de trabalho e pela educação, enfrentando o capital representado pelos grandes proprietários e pelos poderes públicos, teremos conceitos vazios de classe e de educação. A crítica que fazemos à concepção de educação restrita ao espaço e ao tempo de escola não significa negar a instituição escolar ou deixar de reconhecer sua importância para os trabalhadores do campo e da cidade, principalmente o direito à educação, que é universal. Mais do que uma promessa da modernidade, a escola básica pública é uma conquista dos movimentos operários revolucionários, em lutas que se estenderam 
de meados do século XIX a meados do século XX. Nosso propósito, na tentativa de construir a concepção de educação popular, é resgatar a relação da educação com o mundo do trabalho, no qual se constituem os sujeitos políticos coletivos que, nas suas práticas sociais e pedagógicas, definem esta educação popular. Como já afirmamos, trata-se, aqui, dos movimentos sociais populares do campo, que reinventam a relação entre trabalho e educação através da pedagogia dos tempos e espaços alternados de trabalho agrícola e aprendizagem escolar.

Popular, também, como dissemos de início, é um termo híbrido que, em determinado momento histórico, se relaciona com uma identificação do povo como terceiro Estado, incluindo a burguesia e os trabalhadores. $\dot{\mathrm{E}}$ também o horizonte para o qual aponta o conceito moderno de educação para a formação do cidadão, dentto dos princípios que impregnam o discurso da Revolução Francesa, para a constituição da escola pública associada ao Estado-nação (LOPES, 1981). A educação popular, destinada a alfabetizar o povo para que este possa ler a Bíblia e responsabilizar-se por sua salvação, sem depender da palavra do padre, está no centro da Reforma protestante (RUDÉ, 1982; PONCE, 1986).

A caracterização do campesinato europeu, a partir da Revolução Russa, implica fazer referência ao pensamento populista que vigorou na Rússia no final do século XIX, estendendo-se ao início do século XX, para o qual era possivel chegar ao socialismo sem passar pelo capitalismo. Para isso, era necessário manter a base comunitária de organização, da posse da terra e da produção e, simultaneamente, desenvolver um trabalho pedagógico de conscientização dos camponeses. Partindo daí, Paiva (1984) faz uma severa crítica ao rumo que tomou a educação popular no Brasil, a qual chama de "populismo pedagógico", caracterizando-a como semelhante ao que ocorrera na Rússia e que a história mostrara os resultados. Nesse país, o que a autora caracteriza como "populismo" refere-se ao movimento de renovação da Igreja Católica ortodoxa e de valorização da cultura populat, principalmente do camponês, junto com o questionamento da importação cultural de produtos, linguagens e comportamentos europeus; este movimento estava associado a um projeto para o desenvolvimento de uma nação russa.

Para a autora, os documentos e as reflexôes produzidos por pensadores católicos no início dos anos 1960, no Brasil, apresentavam bastante 
semelhança com o populismo russo. Embora não se propusessem a evitar o capitalismo, porque este já estava instalado, manifestavam preocupação com o custo social do desenvolvimento econômico, principalmente do processo de industrialização, e formulavam um projeto nacional ressaltando a originalidade do povo brasileiro. Nessa perspectiva, segundo a autora, cabia aos educadores e intelectuais irem ao povo, escutarem a sua palavra e aprenderem com ele. "A pedagogia popular compatível com tais posiçôes não podia assentar-se sobre a transmissão de conteúdos: - deveria visar à formação de pessoas críticas capazes de exprimir o seu pensar autônomo" (PAIVA, 1984, p. 246). Essa concepção, de certa forma, anulava o potencial educativo do conhecimento socialmente produzido para concentrar-se na valorização do saber popular; esvaziava os conteúdos dele resultantes e retirava do professor o papel social de transmitir os conhecimentos curriculares, pois the cabia colocar-se no mesmo nível dos alunos. Assim:

A tarefa da educação popular seria a de criar condições entre os "dominados" para a contestação e rejeição da estrutura social dividida entre os que pensam, decidem e controlam e os que executam as tarefas decididas por outtos em função dos seus interesses, para que aqueles que tradicionalmente executarn tarefas passem a pensar e a decidit a respeito de tudo o que thes disser respeito. (PAIVA, 1984, p. 250).

Entre suas conclusões, a autora define este populismo como conservador e forjado em uma visão romântica do povo, o que conduz a uma postura imobilista com relação ao papel do educador das classes populares, nas suas relações com a sociedade e nas possibilidades de intervenção nestas relações.

Este artigo de Vanilda Paiva despertou muitas críticas, principalmente na III Conferência Brasileira de Educação - CBE, realizada em Niterói/ RJ em 1984. Concordamos, por um lado, que ela traz questões pertinentes quanto à formulação de uma idéia abstrata de povo, retirada das condições materiais e históricas em que este se faz como tal. Na sua crítica ao "populismo pedagógico", ficamos com a impressão de que, para este, as idéias do povo são "inatas", sendo necessário, apenas, que o educador popular as "parteje", como pensava Sócrates a respeito da maiêutica. Por outro lado, Paiva estabelece uma comparação entre o "populismo 
pedagógico", no Brasil, e o populismo russo, amparada numa análise superficial deste último, principalmente, porque, na análise feita pela autora, em ambos os casos, parece ocorrer uma perda essencial, que é a da dimensão histórica desses dois fenômenos. Além do mais, não se pode esquecer que o trabalho de educação popular feito na época à qual a autora se refere deu visibilidade às classes populares, como sujeitos de educação e de lutas por emancipação social, que têm sido tratadas apenas como objetos de políticas assistencialistas.

Outra abordagem crítica efetuada por Paiva (1985) é sobre a educação permanente. Assim, pensamos que não se poderia dar continuidade a essa discussão sobre o sentido e o conteúdo da educação popular sem estabelecer uma diferença entre esta e o que é conhecido como educação permanente, bastante divulgada nos anos 1970. Durante o governo militar, principalmente no final dos anos 1960 e nos anos 1970, difundiu-se amplamente a idéia de que a educação ocorria "durante toda a vida", com métodos formais ou informais, através de cursos oficializados e com certificação ou através de cursos e encontros, que não ofereciam certificados. Era identificada como educação permanente, e seu uso aconteceu pela primeira vez em 1960, segundo Collet (1976), no Congresso Mundial de Educação de Adultos, realizado pela Organização das Nações Unidas para a Educação, a Ciência e a Cultura - UNESCO, em Montreal, no Canadá. Para esta autora, sua compreensão “[...] não pode ser reduzida à idéia de educação 'extra-escolar', 'prolongada' nem 'educação de adultos' porque estas não iriam corresponder à necessidade de reformular o sistema educacional a partir de uma opção pela educação permanente" (COLLET, 1976, p. 18).

Contrapondo-se à posição de defesa da educação permanente feita por Heloisa Gouvêa Collet na obra anteriormente citada, Paiva (1985) pergunta se esta modalidade de educação, difundida através da publicação de textos, principalmente de autores franceses, pela Revista Brasileira de Estudos Pedagógicos (RBEP), no final dos anos 1960, seria “[...] uma ideologia educativa ou necessidade econômico-social?”. Na época em que publicou pela primeira vez este texto, em 1977, na Revista Sintese, a autora associava o surgimento da educação permanente às necessidades da produção e distribuição de mercadorias, "[...] na fase tardia do capitalismo, na qual a automação se propaga passo a passo (derivando, portanto, da necessidade de reciclagem e da disponibilidade para 'aprender a aprender') [...]" (PAIVA, 1985, p. 109). Para a 
autora, que faz uma abordagem crítica do conceito de educação permanente, esta tem sua origem nas necessidades de qualificação, através de processos de reciclagem, emanadas de mudanças nos processos produtivos do sistema capitalista, na fase que identifica como "capitalismo tardio".

Reconhecendo "contradições, conflitos e ambigüidades" entre "educação permanente" e "educação popular", expressões relacionadas às experiências dos movimentos sociais, no Brasil, João Francisco de Souza faz sua opção por esta última, que vern estudando há vátios anos. Afirma que o conceito de educação popular vem passando por um processo de reconstrução através de três movimentos simultâneos ocorridos nos anos 1990. Para o autor:

Esses processos se conectam com uma tradição de educação popular que vem se desenvolvendo a partir das experiências e reflexões de Paulo Freire no Nordeste brasileiro e, em seguida, no mundo, e se vêem hoje desafiados por novas tarefas, colocando-nos diante de realidades diferentes, de outros sujeitos e de cenários emergentes. (SOUZA, 2007, p. 47).

Experiências de educação popular e estudos sobre esta temática estão bastante próximos a experiências e estudos sobre cultura popular. Stuart (2003), em "Notas sobre a desconstrução do popular", ao tentar desconstruir/construir o conceito de cultura popular, nos oferece uma definição que preenche o que vimos tentando formular para a compreensão de educação popular. O autor reconhece que, embora não sejam sinônimos, os termos "popular" e "classe" estão profundamente imbricados, o que coincide com o que pensamos, que a classe é o elemento definidor do popular. Mesmo considerando os limites de uma definição que carrega um conflito de forças, Stuart (2003, p. 241) pensa que nesta é necessário considerar, "[...] em qualquer época, as formas e atividades cujas raizes se situam nas condições sociais e materiais de classes especificas, que estiveram incorporadas nas tradições e práticas populares". Sobre a cultura popular, seu objeto de análise neste artigo, afirma que "[...] cruamente falando e de uma forma bem simplificada, o que conta é a luta de classes na cultura ou em torno dela" (STUART, 2003, p. 242).

Trazendo a discussão sobre a educação popular para a América Latina, Marco Raúl Mejía Jiménez é um dos seus estudiosos. Para quem se propõe a 
acompanhar o desenvolvimento da educação popular latino-americana, este autor (JIMÉNEZ, 2004, p. 20) recomenda a necessidade de abandonar:

- a pretensão de pensarmos a educação popular numa perspectiva messiânica de transformar o mundo;

- a visão maniqueísta sobre a educação, que nos faz categorizar uma educação popular como a única verdadeira e as demais como falsas e equivocadas, porque, com isso, não construímos pontes entre os conhecimentos e os saberes, entre as culturas populares e a cultura universal;

- a escola formal como um lugar em que só ocorre a reprodução social, e não "[...] como campo de conflito em que diferentes interesses pugnam pela sua reconstrução".

Nessa mesma perspectiva, Orlando Fals Borda, educador-pesquisador colombiano, discute o conceito de conscientização, central na concepção de educação popular de Paulo Freire. Este conceito, cuja construção iniciou-se no Brasil, teve continuidade em uma experiência concreta de melhoramento das condições de vida e de trabalho de camponeses no Chile nos anos 1960, após a saída de Freire do nosso país, e em um contexto no qual era possível projetar uma transformação radical da sociedade. $\mathrm{O}$ uso posterior do conceito de conscientização em outros paises fez com que, aos poucos, a sua compreensão fosse esvaziada do sentido original, que era o conteúdo revolucionário e libertador da conscientização. Segundo Fals Borda (1994), foram cooptados os sentidos originais presentes na experiência de Freire. "O que aparecia no contexto chileno como algo revolucionário e positivo, ao passar ao Haiti, ao passar à Colômbia, recebeu um sentido integracionista e muitas vezes contra-revolucionário" (FALS BORDA, 1994, p. 11). Na Colômbia, a conscientização esteve articulada ao Programa de Desenvolvimento Rural Integrado - PDRI, um paliativo econômico-político aplicado no Brasil nos anos 1970. É importante destacar esta afirmação do autor de que "[...] Piaget parecia influir mais do que Marx neste paradigma da conscientização, ainda que Paulo Freire tenha reconhecido a influência de Marx em sua concepção de educação" (FALS BORDA, 1994, p. 12).

A incapacidade deste conceito de continuar iluminando a compreensão de uma educação associada a um processo de transformação da sociedade gerou uma crise e a busca de superá-la. O núcleo central da crítica ao 
paradigma da conscientização radica-se na idéia de que a libertação como um processo social não é um problema de tomada de consciência, mas uma prática de transformação informada e articulada pelo conhecimento da opressão. Nos anos 1970, em busca de um novo paradigma, retomase, segundo o autor, o conceito marxista de práxis, que, embora estivesse implícito na conscientização, não recebia o devido destaque. Fals Borda (1994) explica esse processo apelando à histórica divisão entre teoria e prática, sendo esta subordinada àquela.

Essa descoberta por parte de alguns estudiosos da Sociologia os levou à adoção do método de investigação-ação, no início de 1970, embora este não estivesse imune à tradição sociológica e à cooptação, caindo, também, numa postura integracionista. A questão evoluiu para a relação entre sujeito e objeto de investigação, em que o pesquisador, como sujeito, estaria imune às influências de seu objeto, mesmo que esse fosse constituído por pessoas. A recomendação era "devolver" o conhecimento aos sujeitos, mantendo a separação entre investigador e investigado. O critério, para Fals Borda, é romper com a separação clássica entre sujeito e objeto. Já não é somente práxis, mas investigação-ação participativa. $O$ autor finaliza seu trabalho afirmando que a questão não se encerra com uma resposta única, mas vai sedimentando um pensamento comum.

Porque os problemas de nossos países cada vez mais se agudizam e é necessário estar presente no processo com ferramentas adequadas. Já se conseguiu transcender aquele paradigma da conscientização. Agora estamos vivendo outro paradigma que é o da participação. Não nos deixemos enganar com o desenvolvimento deste novo paradigma; não nos deixemos cooptar, nem nossas idéias nem nossas pessoas. Já se tem dito aqui que tanto a educação popular quanto a investigação participativa têm efeitos políticos inevitáveis. (FALS BORDA, 1994, p. 15).

Fals Borda (1982) também analisa a participação popular na produção da ciência, ao propor os aspectos teóricos da pesquisa participante. Tendo por referência empírica trabalhos de educação popular e de investigaçãoação participativa realizados na Colômbia, o autor tece críticas à atuação dos cientistas sociais, muito próximas às anteriormente feitas por Vanilda Paiva 
no que esta caracterizou como "populismo pedagógico". Aquele autor critica a postura dos intelectuais que saíram das universidades para "assimilar" o homem do povo, o que significou "[...] uma básica falta de respeito pela cultura e filosofia do homem comum" (FALS BORDA, 1982, p. 49). A educação popular e a investigação-ação participativa têm desdobramentos políticos, o que nos impõe a disciplina de estarmos atentos para não nos enganarmos e, direta ou indiretamente, acabarmos por defender a atual ordem social.

Podem-se depreender desses estudos a riqueza e, ao mesmo tempo, a complexidade do popular, que são próprias das relações sociais contraditórias em que este se constrói como tal, mas não só, pois nessa construção há outros elementos a considerar, como a cultura, a história, a experiência. Thompson (1981) reconhece tanto a validade quanto os limites da experiência, porque esta é produzida dentro de relações sociais determinadas, permeadas por uma gama de elementos culturais, lingǘsticos, mas, principalmente, relacionados ao trabalho e às formas de vida geradas por este. A dificuldade, então, e tendo em conta esses limites, é captar, é apreender essa experiência que é vida e, portanto, é movimento. Quase se poderia dizer que a experiência aqui configurada por Thompson se aproxima do que Gramsci $(1981$; 1990) identifica como senso comum, carregado este de contradições. Mas a experiência é ainda mais rica do que o senso comum, porque corresponde a um saber acumulado através do trabalho, que é necessário para responder aos desafios colocados pelo cotidiano dos movimentos sociais populares do campo. Parece-nos, então, que a educação popular dá conta da abrangência das experiências pedagógicas realizadas por esses movimentos que estamos focalizando.

$\mathrm{Na}$ América Latina, povos indígenas, negros descendentes de escravos africanos que se tornaram quilombolas, camponeses e famílias pobres, brancos, negros, indios e mestiços que vivem do trabalho informal não cabem no conceito "classe operária". Mas também não podem ser enquadrados como classe proprietária de terras e capital, nem como lumpemproletariado, ao qual Marx ([198-?]) se refere como "o lixo de todas as classes". Seus processos organizativos e de luta escapam aos modelos europeus; quando muito, se aproximam do conceito de classes subalternas de Antonio Gramsci ou, como já afirmamos anteriormente, de classes populares, sem perder de vista as contradições próprias de suas formas 
de inserção nas relações sociais de produção, através do mercado. Essas populações vêm lutando há séculos; organizam-se em movimentos sociais populares, criando alternativas de sociedade e de educação que pressupõem um projeto de emancipação social.

No Brasil, o que identificamos como povo, tendo claro o recorte de classe que antes afirmamos, corresponde à maioria da população pobre, que vive no campo como nas favelas urbanas, que são brancos, índios aculturados, caboclos, negros e mulatos, são os "sem" o essencial para uma vida digna, os sem-terra, os sem-trabalho, os sem-teto, os sem-educação, os sem-saúde, os sem-segurança... Mas essas pessoas não se entregam à condição de "sem"; elas se organizam, se articulam, e se põem

[...] em movimento contra a exploração, a dominação, a violência porque sabem as suas causas, tornam-se o "povo político", constituem os chamados movimentos sociais populares. [...] Portanto, o popular é plural, complexo, multifacetado, apresenta marcas de conformismo, mas também de resistência e de rebeldia. (PALUDO; BEATRICI, 2007, p. 10).

Sem entrar na análise de suas lutas históricas, porque isso nos afastaria dos objetivos propostos para este artigo, apontamos essas populações que lutam por seus direitos, mais precisamente, os movimentos sociais populares, identificados como sujeitos políticos coletivos, forjadores de educação popular. Essas práticas/concepções, ainda em processo de construção, projetam uma reconfiguração da escola. Paludo (2001), ao analisar a educação popular no processo de constituição de um campo democráticopopular, ressalta o papel das organizações populares como protagonistas de projetos sociais e educacionais populares. Para Paludo (2001, p. 204), podemos apontar como uma das "[...] condições para o restabelecimento de identificações mais próximas, a construção e o resguardo da autonomia das organizações populares e do seu protagonismo tanto cotidiano, quanto nos espaços públicos e na sociedade". Nesta observação, a autora mostra a necessidade de estarmos atentos para que as iniciativas de educação popular, dentro dos movimentos sociais populares, não sejam cooptadas seja por partidos, seja por igrejas, seja pelo Estado, seja por outras organizações que financiam as experiências, colocando, no cerne de sua análise, a autonomia dos movimentos sociais populares e de suas iniciativas. Paludo (2001), 
entretanto, identifica a educação popular como uma das concepções construídas dentro de um projeto de modernidade brasileira e latinoamericana. Por isso, utiliza-se, nesta obra, da expressão educafão do popular.

Designa-se, com ela, uma compreensão da educação
instituída, pública ou não, como uma prática social
construída historicamente. Esta prática social e histó-
rica se faz mediada por sujeitos políticos e recursos,
que articulam em torno de si diferentes campos de
forças políticas e culturais. Estas forças disputam
entre si a direção para as práticas educativas (fins e
meios) e articulam-se de forma orgânica com pers-
pectivas de determinados direcionamentos (projetos)
econômico, político e cultural da sociedade no seu
conjunto. (PALUDO, 2001, p. 65).

Concordamos com esta definição da autora. Todavia, mantemos o conceito de educação popular, que conceptualizamos por sua historicidade e pelo corte de classe. Corremos, com isso, o risco de sofrer a crítica por uma opção que, no caso, seria ligada a uma época e a um projeto de desenvolvimento que, portanto, estariam ultrapassados. Não nos parece que seja assim, pois afirmamos que os conceitos, como os sujeitos que os produzem a partir de determinadas práticas sociais, são históricos, assumem formas e conteúdos novos, conforme o contexto em que empreendem suas lutas e produzem suas reflexões. Todavia, mantêm uma unidade no que tange à configuração de classe subalterna ou popular que assume na luta de classes; existe, portanto, uma imbricação profunda entre os movimentos sociais populares e a educação (RIBEIRO, 2004).

Do que foi analisado até aqui, com a preocupação de definir a educação popular, e partindo da consideração anterior feita por Paludo (2001) a respeito da autonomia dos movimentos sociais populares, identificamos diferentes concepções/práticas de educação popular no Brasil. Essas correspondem a três momentos históricos que nos ajudam a entender os conceitos que emergem das experiências pedagógicas oriundas dos movimentos sociais populares do campo. Como há vários estudos que registram esta história, vamos fazer uma sintese no que interessa ao objetivo deste artigo, abordando os três períodos, correndo o risco de deixar muitas lacunas e tendo a clareza de que podem existir outras leituras. 
O primeiro corresponde aos anos 1950 até o golpe militar de 1964, período identificado como populismo, voltado à construção de um projeto de desenvolvimento econômico nacional. Neste periodo, localiza-se a educação popular vinculada às campanhas de alfabetização associadas ao que se pretendia como conscientização, em que pode ser compreendido o Método Paulo Freire, além dos trabalhos de cultura popular e de educação de base. Havia professores, estudantes universitários, secundaristas, artistas, intelectuais engajados naquele projeto nacional de desenvolvimento.

Mas essa questão da educação popular, como um caminho de libertação, não está dissociada dos movimentos sociais que ocorrem fora do País na mesma época. A "educação do colonizador", que no Brasil servirá de preâmbulo às reflexões que antecedem a "pedagogia do oprimido", formulada mais tarde por Paulo Freire, é uma questão que emerge no contexto das lutas de libertação nacional de colônias, principalmente africanas, nos anos 1950. Embora a independência formal dos países latino-americanos tivesse acontecido há mais de um século, as guerras de libertação que ocorriam na África, mas também no Vietnã e na Indonésia, expandiam para aqueles países o debate sobre a "emancipação nacional", que se distancia enormemente do que as experiências pedagógicas apontam hoje como emancipação humana.

Paiva (1979) situa a "pedagogia do oprimido" dentro de um projeto nacional de desenvolvimento ou de emancipação nacional. Para a autora, este projeto está carregado de contradições porque desconsidera o antagonismo das classes sociais no capitalismo, já instaurado no Brasil. Ao invés disso, questiona a autora, o problema se desloca para a crítica ao colonialismo e à educação do colonizador. Para ela, se a pretensão é formular um projeto de transformação da sociedade, é imprescindível que tenhamos à mão categorias mais precisas. Se a “[...] 'pedagogia do oprimido' é a pedagogia das classes dominadas, a pedagogia camponesa, a pedagogia operária, a pedagogia comprometida com a transformação profunda das estruturas sociais" (PAIVA, 1979, p. 12), então, ela precisa ser inserida no contexto dos antagonismos de classe e das lutas que decorrem daí.

É importante destacar que o populismo, no qual se insere a educação popular neste primeiro periodo, está compreendido dentro do projeto de desenvolvimento pensado para o Estado nacional, pelos seus dirigentes, incluindo a participação popular para o apoio às reformas de base propostas 
pelo governo João Goulart. A Igreja católica, como instituição, tendo por base a sua doutrina social, também está incorporada neste projeto, do mesmo modo que as universidades e, principalmente, os movimentos estudantis (PAIVA, 1983).

Nessa mesma direção, Solano (1996) faz um estudo da pessoa e da obra de Paulo Freire, tomando como referência as épocas, os contextos sociais e as experiências vivenciadas pelo educador pernambucano. Para isso, demarca quatro épocas. A primeira começa em meados dos anos 1950 e se estende até o golpe militar, no Brasil, em 1964, quando Paulo Freire sofre a perseguição política. Esta época é caracterizada por Solano (1996, p. 6) como "[...] do dirigismo explícito ao populismo induzido". É nesta fase que se situam as concepções e práticas de diálogo, baseadas na compreensão do homem como um ser de relações; da conscientização como possibilidade de superar uma sociedade autoritária, em que não há diálogo; da possibilidade de atingir a modernização; e das fichas de cultura, compreendidas nos Círculos de Cultura do Movimento de Cultura Popular. Dentro deste movimento, se desenvolve a Educação de Adultos, principalmente a alfabetização associada à formação para a participação política. "O populismo induzido não era, então, uma prerrogativa do questionamento freireano, era basicamente uma expressão da época" (SOLANO, 1996, p. 18).

Nas fichas de cultura é onde se observa com maior nitidez a influência do culturalismo e do existencialismo, pois seu propósito era que os analfabetos se dessem conta de sua condição humana. As fichas de cultura são estratégias para que $o$ adulto analfabeto se questione sobre a sua vida e a sua realidade. A razão e a cultura explicariam o curso da história. Por isso, para Solano (1996, p. 21): "Não é gratuito que no próximo livro de Freire - Pedagogia do Oprimido - depois do contato com o Chile de Frei e com o marxismo, as fichas de cultura sejam omitidas" (SOLANO, 1996, p. 21).

Nesta fase, porém, a iniciativa da educação popular não é dos sujeitos coletivos que começam a se organizar nos processos de luta pelas reformas de base, entre elas a Reforma Agrária, muito embora a proposta de Paulo Freire, pela primeira vez, os coloque como sujeitos de educação, de participação, de desenvolvimento social. É no método de alfabetização, que considera os saberes das práticas sociais do povo analfabeto, que parte delas e retorna a elas compreendidas e decifradas, que reside a diferença ou o 
novo desta proposta pedagógica que toma os alfabetizandos, principalmente camponeses, como sujeitos de saberes e de conhecimentos (FREIRE, 1979; 1980; BARREIRO, 1980). Através de um processo de conscientização, esses poderiam se inserir na construção de um projeto nacional. Porém, não se pode dizer que esta educação popular se caracterize pela autonomia, porque ela não é obra dos sujeitos, embora dela participem. A liberdade, a autonomia e a emancipação nessas experiências só fazem sentido em relação ao projeto nacional desenvolvimentista em que estavam inseridas.

Solano (1996, p. 22) amplia essa discussão incorporando a experiência de Paulo Freire no Chile, identificada como "[...] da tomada de consciência (conscientização) à prática social: seu encontro com o marxismo". Esta etapa se inicia com a obra Pedagogia do oprimido (FREIRE, 1981) e é marcada pelo deslocamento do conceito de homem para o de classe social, com a compreensão das relações sociais de produção e da dependência da sociedade brasileira em relação ao capitalismo internacional. Outra mudança se dá no conceito de prática social, associado à transformação social, que vem a substituir o de conscientização, como percepção crítica da realidade. Com isso, e segundo Solano (1996, p. 24), Freire passa de uma concepção abstrata de transformação para a de ação organizada, sem, no entanto, especificar esta ação. Acrescenta, ainda, que Freire, nesta época, reconhece que o educador exerce uma diretividade parcial sobre o educando.

Retomando a caracterização dos três períodos, tal como proposta antes, a segunda concepção começa a emergir nos processos organizativos de resistência à ditadura militar no final dos anos 1970, coincidindo com a retomada das lutas operárias e camponesas que dariam origem às centrais sindicais, à emergência de partidos de esquerda, alguns na clandestinidade, e ao Movimento dos Trabalhadores Rurais Sem Terra - MST'. Uma nova percepção de classe trabalhadora brasileira é produzida nesse período, rompendo com leituras que analisavam as organizações dos trabalhadores em negativo, como objetos do processo de industrialização ou da ação manipuladora do Estado.

Vistos tradicionalmente como personagens subordinados ao Estado e incapazes de impulsão própria e, após 1964, silenciados e atomizados politicamente pelo regime militar, eles irrompem na cena política em 1978, falando por boca própria e revelando a 
existência de formas de organização social que haviam tecido à margem dos mecanismos tradicionais montados para representá-los e que serviam para a sua cooptação, enquadramento e controle. (PAOLI; SADER; TELLES, 1983, p. 130).

Nesse processo, destaca-se a presença da Igreja Católica, que cedeu espaço, nos seus seminários, escolas e paróquias, às organizações dos trabalhadores durante a ditadura, tendo por base a Teologia da Libertação. Esta é elaborada a partir das discussões das Conferências Episcopais LatinoAmericanas - CELAM, realizadas em Medellín, na Colômbia, em 1968, e em Puebla, no México, em 1979, onde a Igreja Católica latino-americana faz a "[...] opção preferencial pelos pobres". (LÖWY, 1991; COSTA, 1992). Há uma preocupação, tanto das organizações sindicais quanto das pastorais populares, de formação de lideranças para a organização das oposições sindicais e para a disputa político-partidátia. Nisto consiste a educação popular. Neste segundo período, pode-se observar uma maior autonomia dos movimentos sociais em relação à presença do Estado, o qual percebem com desconfiança, como um poder ditador.

No início de 1980 , ainda em plena ditadura militar e a partir das leis e dos programas educacionais impostos por esta, cunhou-se uma visão negativa da educação. Esta passou a ser vista como um programa formalizado que "[...] é parte do aparato de que classes sociais ou grupos de controle do poder político lançam mão para realizar alguns de seus interesses e objetivos políticos de domínio, ocultos sob propostas de 'democratização', através da educação" (BRANDÃO, 1980, p. 7). Também se fazia uma crítica ao distanciamento da escola em relação ao seu entorno e aos saberes das crianças das classes populares, conforme identifica Fischer (1986, p. 44), ao afirmar que "[...] há todo um processo educativo acontecendo ao redor da Escola, e, no entanto, esta parece desconhecer ou, pelo menos, não entendê-lo como tal".

Conforme Paiva (1984, p. 16), um conjunto de fatores contribuiu para essa desconfiança sobre qualquer modalidade de educação popular que fosse de autoria do Estado, incluindo a educação oferecida nas escolas públicas. "A escola e os programas educacionais do Estado não seriam populares porque estariam a serviço exclusivo da reprodução social e da legitimação da ordem e do regime." Nesse processo, ainda de acordo com a autora, 
ampliou-se o conceito de educação, incluindo, assim, "[...] o "conjunto da vida civil' das populações, arrastando seus defensores a uma 'pedagogização' da vida cotidiana e de todas as formas de luta social" (PAIVA, 1984, p. 17). Incluímo-nos entre esses "defensores" do alargamento do conceito de educação, sem, no entanto, abrir mão do direito à escola pública, que a autora declara ter sido abandonado naquele momento. A desconfiança em relação à escola pública também pode ser explicada pela produção e divulgação, nos anos 1970-80, das teorias chamadas "crítico-reprodutivistas", conforme análise em Saviani (1983) e Ribeiro (1999b). Mas, na época, ocorre uma dependência, no caso da Igreja, que cede os espaços e os recursos, através de centros de formação para a realização de encontros, cursos e elaboração de material didático, como as cartilhas populares. A educação popular é feita, então, pelos sindicatos associados às pastorais populates.

Nesse periodo, a preocupação maior é com o fortalecimento das organizações sindicais e com a conquista de sua autonomia, principalmente em relação ao Estado. A emancipação social, portanto, ainda não está colocada nesta fase. A questão da liberdade, para os movimentos sociais populares, aparece vinculada à cidadania, na luta por direitos sociais básicos, entre eles, a uma educação pública de qualidade.

Um terceiro período tem início nos anos 1990, quando a adoção do modelo flexível de acumulação em substituição ao taylorismo-fordismo, associada à reação neoliberal de esvaziamento do Estado social, começa a produzir seus efeitos. Estes se mostram, principalmente, através do desemprego, no enfraquecimento dos sindicatos e das centrais sindicais de trabalhadores, principalmente da Central Única dos Trabalhadores - CUT, criada em 1983 pelos sindicatos combativos de trabalhadores do campo e da cidade. A Igreja Católica também experimenta uma reação conservadora, com a eleição do Papa Carol Woytila, que recebeu o nome de João Paulo II, retirando seu apoio aos trabalhos pastorais associados aos movimentos sociais populares. Mantiveram-se, no caso dos movimentos sociais populares do campo, aqueles setores ligados à Comissão Pastoral da Terra - CPT e ao Conselho Indigenista Missionário - CIMI, entidade religiosa ecumênica de apoio à causa indígena.

O MST, que já tem uma caminhada histórica, mantém sua independência em relação ao Estado, com o qual se confronta na luta pela reforma agrária. Nesse período, o Movimento também começa um 
processo de autonomização da Igreja, sem, com isso, dispensar o apoio, principalmente da CPT e da Conferência Nacional dos Bispos do Brasil - CNBB, que, junto com outras organizações, constituem a Articulação Nacional por uma Educação do Campo ${ }^{1}$, com o apoio desta que se realiza a I Conferência Nacional por uma Educação Básica do Campo em 1998, com a participação de todos os movimentos sociais populares de luta pela terra, incluindo a Confederação dos Trabalhadores na Agricultura - CONTAG e as federações de trabalhadores rurais.

É importante ressaltar que é nesse periodo que a reivindicação de uma educação do campo é formulada pelos sujeitos políticos coletivos organizados e presentes naquela Conferência. $O$ apoio das entidades financiadoras da Conferência não interferiu nas definições das propostas de educação do campo formuladas pelos movimentos sociais populates, mesmo considerando as suas contradições internas e as divergências de projetos sociais das entidades e organizações sociais, sindicais e movimentos sociais populares presentes. Não só a liberdade de ação e a autonomia em relação a outras instituições se afirmam nesse periodo, mas, sob a liderança do MST, coloca-se no horizonte a conquista da emancipação social associada à construção do projeto popular de sociedade identificado com o socialismo. Pode-se afirmar, então, que, nesse período, a educação popular, como projetada pelos movimentos sociais populares do campo, começa a assumir uma identidade própria, refletindo um avanço na caminhada pela liberdade, autonomia e emancipação social. Mas, como estamos vendo, os conceitos se constroem, e as práticas se realizam em um campo de relações de forças antagônicas, portanto, com avanços e retrocessos. Conquistas como o Programa Nacional de Educação da Reforma Agrária PRONERA mostram isso. Mas não vamos aprofundar esta questão porque extrapolariamos nossos objetivos.

O conhecimento científico que pretende apreender o movimento das classes sociais e as possibilidades de transformação social sem partir da cultura popular e do ponto de vista das classes populares estará, de um lado, separando, no processo histórico, o sujeito e o objeto, e, de outro, universalizando-os a partir de uma suposta visão universal "[...] do outro, do 'mais avançado', sem considerar que a universalidade está na superação de ambos" (MARTINS, 1989, p. 114). É na duplicidade da cultura popular $e$, conseqüentemente, da educação popular que se podem captar a luta 
de classes, as relações de antagonismo que as classes mantêm entre si, a identificação do dominador e do dominado, do vencedor e do vencido, que, inclusive, criam códigos nos quais se imbricam o obedecer $e$ o desobedecer, o negar e o afirmar, o lutar e o resistir...

Sintetizando a construção do que compreendemos por educação popular, afirmamos nossa concordância com Silva (2006), a qual propõe o alargamento do conceito de educação, que seria assim definida:

A educação é uma prática social que tem o objetivo de contribuir, direta e intencionalmente, no processo de construção histórica das pessoas e, nesse sentido, os movimentos sociais, como as práticas sócio-políticas e culturais constitutivas de sujeitos coletivos, têm uma dimensão educativa, à medida que constroem um repertório de ações coletivas, que demarcam interesses, identidades sociais e coletivas, que visam a realização de seus projetos por uma vida melhor e da humanização do ser humano. (SILVA, 2006, p. 62).

Há, hoje, um processo de autonomização dos movimentos sociais populares que constroem a unidade na luta pela democratização da sociedade na diversidade de seus interesses particulares ligados ao trabalho e à cultura, e que determinam suas formas de organização. A educação popular, nesse sentido, tanto se aproxima da herança de Paulo Freire como retoma experiências de trabalho-educação efetuadas na Rússia após a Revolução Bolchevique. Dentre essas, destacam-se as que estão registradas nas obras de Pistrak (2003) e Makarenko ([198-?]), cuja influência é maior nas experiências pedagógicas de trabalho agricola e educação escolar em tempos/espaços alternados, na Fundação de Desenvolvimento e Educação da Região Celeiro - FUNDEP e no Instituto Técnico de Capacitação e Pesquisa da Reforma Agrária - ITERRA.

Três elementos centrais, baseados em Pistrak (2003), orientam as experiências de educação popular da FUNDEP e do ITERRA, direcionados à construção de uma pedagogia social: a relação entre trabalho e educação; a auto-organização dos educandos e a metodologia do ensino organizada a partir dos complexos temáticos. $\mathrm{Na}$ concepção de Makarenko, a escola associa princípios da instrução geral com trabalho produtivo; retira a centralidade da sala de aula e, para além da instrução, projeta a educação do 
coletivo. Para este educador, educação popular é educar as massas segundo a lei da luta de classes.

$\mathrm{Na}$ atualidade, a educação popular projetada pelos movimentos sociais populares rurais/do campo começa a assumir identidade própria, refletindo o avanço da caminhada pela liberdade como cidadãos, pela autonomia que relaciona o direito ao trabalho à posse da terra, e pela emancipação social como o horizonte das lutas que unem as classes populares.

\section{Notas}

1 A Articulação Nacional por uma Educação do Campo tem o apoio da Conferência Nacional dos Bispos do Brasil (CNBB); do Movimento dos Trabalhadores Rurais Sem Terra (MST); da Universidade de Brasilia (UNB); da Organização das Nações Unidas para a Educação, a Ciência e a Cultura (UNESCO); e do Fundo das Nações Unidas para a Infância (UNICEF) (KOLLING; IR. NERY; MOLINA, 1999, n. 1).

\section{Referências}

ARROYO, Miguel Gonzalez; CALDART, Roseli Salete; MOLINA, Mônica Castagna. Por uma educaf̧ão do campo. Petrópolis/RJ: Vozes, 2004.

BARREIRO, Júlio. Educaşão popular e conscientizą̧ão. Petrópolis/RJ: Vozes, 1980.

BRANDÃO, Carlos Rodrigues. Concepções e experiências de educação popular. Cadernos do Cedes, São Paulo, n.1, p. 5-34, 1980.

CALDART, Roseli Salete. Escola é mais do que escola..: pedagogia do movimento sem terra. Petrópolis, RJ: Vozes, 2000.

COLLET, Heloisa Gouvêa. Educa̧̧ão permanente: uma abordagem metodológica. Rio de Janeiro: SESC, 1976.

COSTA, Márcio. Educafão e libertafão na América Latina. Campo Grande: Cefil, 1992.

FISCHER, Nilton Bueno. O educativo nas lutas populares. Revista de Educafão AEC, São Paulo, n.61, jul., p. 39-44, set. 1986. 
FREIRE, Paulo. Ação cultural para a liberdade. 4. ed. Rio de Janeiro: Paz e Terra, 1979.

FREIRE, Paulo. Conscientizạãa: teoria e prática da libertação: uma introdução ao pensamento de Paulo Freire. São Paulo: Moraes, 1980.

Pedagogia do oprimido. 9. ed. Rio de Janeiro: Paz e Terra, 1981.

GRAMSCI, Antonio. Conceppão dialética da bistória. 4. ed. Rio de Janeiro: Civilização Brasileira, 1981.

. Poder, politica e partido. São Paulo: Brasiliense, 1990.

JIMÉNEZ, Marco Raul Mejía; AWAD, Myriam Inés. Educación popular boy: en tiempos de globalización. Bogotá: Aurora, 2004.

FALS BORDA, Orlando. Aspectos teóricos da pesquisa participante: considerações sobre o significado e o papel da ciência na participação popular. In: BRANDÃO, Carlos Rodrigues (Org.). Pesquisa participante. 2. ed. São Paulo: Brasiliense, 1982. p. 34- 41.

La investigación: obra de los trabajadores. 6 ed. Santafé de Bogotá: Dimensión Educativa, 1994. (Aportes, 20), p. 9-6.

KOLIING, Edgar; NERY, Irmão; MOLINA, Mônica Castagna. Por uma Educacãa Básica do Campo. Brasillia, DF: Articulação por uma Educação Básica do Campo, 1999. (Coleção Por uma Educação Básica do Campo, 1).

LOPES, Eliane Marta Santos Teixeira. Origens da educação pública: a instrução na revolução burguesa do século XVIII. São Paulo: Loyola, 1981.

LÖWY, Michael. Marxismo e teologia da libertaģão. São Paulo: Cortez; Autores Associados, 1991.

MAKÁRENKO, Anton Semionovitch. Poema pedagógico. En tres partes. Moscú: Progreso, 193... Traducido del ruso con presentación de S. Telingater. $3 \mathrm{v}$.

MARTINS, José de Souza. Caminhada no chão da noite: emancipação política e libertação nos movimentos sociais do campo. São Paulo: Hucitec, 1989.

MARX, Karl. O dezoito brumário de Luís Bonaparte. MARX, Karl; EN-

GELS, Friedrich. Obras escolbidas. São Paulo: Alfa-Omega, [198-?] v. 1, p. 199-285. 
PAIVA, Vanilda. Introdução. In: (Org). Perspectivas e dilemas da educação popular. Rio de Janeiro: Graal, 1984. p. 15- 60.

Anotações para um estudo sobre populismo católico e educação no Brasil. - (Org.). Perspectivas e dilemas da educafão popular. Rio de Janeiro: Graal, 1984. p. 227 - 266.

Educação permanente: ideologia educativa ou necessidade econômico-social? Educação Permanente e capitalismo tardio. In: PAIVA, Vanilda; RATTNER, Henrique. Edwcafão permanente e capitalismo tardio. São Paulo: Cortez, 1985.

Do "problema nacional" às classes sociais. Educaf̧ão e Sociedade, São Paulo, n. 3, p. 5-14, maio 1979.

\section{3.}

Educação popular e Educação de Adultos. 2. ed. São Paulo: Loyola,

PALUDO, Conceição. Educação popular em busca de alternativas. Porto Alegre: CAMP, 2001.

; BEATRICI, Rodrigo Ferronato. Sistematização de experiências de trabalho popular. Ronda Alta: FUNDEP, 2007. (Cadernos Práticas Educativas Populares, 1).

PAOLI, Maria Célia; SADER, Eder; TELLES, Vera da Silva. Pensando a classe operária: os trabalhadores sujeitos ao imaginário acadêmico. Revista Brasileira de História, São Paulo, n. 6, p. 129-149, set. 1983.

PISTRAK. Fundamentos da escola do trabalbo. 3. ed. São Paulo: Expressão Popular, 2003.

PONCE, Aníbal. Educa̧ãa e luta de classes. 6. ed. São Paulo: Cortez, 1986.

RIBEIRO, Marlene. De seringueiro a agricultor-pescador a operário metalürgico: um estudo sobre o processo de expropriação/ proletarização/ organização dos trabalhadores amazonenses. 1987. Dissertação (Mestrado em Educação) - FAE/UFMG, Belo Horizonte. $375 f$.

RIBEIRO, Marlene. Universidade brasileira "pós-moderna": democratização x competência. Manaus: EDUA, 1999a.

A originalidade de Paulo Freire no pensamento educacional bra- 
sileiro. Educaşão em Revista, Belo Horizonte, n. 29, p. 15-30, jun. 1999b.

Movimentos sociais e educação: uma relação necessária. Espaço Pedagógico, Passo Fundo, v. 11, n. 1, p. 35-61, 2004 a.

RUDÉ, George. Ideologia e protesto popular. Rio de Janeiro: Zahar, 1982.

SAVIANI, Dermeval. Escola e democracia. São Paulo: Cortez; Autores Associados, 1983.

SILVA, Maria do Socorro. Da raiz à flor: produção pedagógica dos movimentos sociais e a escola do campo. In: MOLINA, Mônica Castagna (Org.). Educaşão do campo e pesquisa: questões para reflexão. Brasilia, DF: MDA, 2006. p. 60-93.

SOLANO, Mariño Germán. El método Paulo Freire: elementos para reconstruir sus propuestas de formación de lectores. Santafé de Bogotá: Dimensión Educativa, 1996. p. 5-26.

SOUZA, João Francisco de. Educação popular e movimentos sociais no Brasil. In: CANÁRIO, Rui (Org.). Educafãa popular e movimentos sociais. Lisboa: EDUCA, 2007. p. 37-80.

STUART, Hall. Notas sobre a desconstrução do popular: cultura e identidade. In: Da diáspora: identidades e mediações culturais. Belo Horizonte: Ed. UFMG, 2003. Parte 3.

THOMPSON, Edward P. La sociedad inglesa del sigo XVIII. ¿Lucha de clases sin clases? In: Tradición: revuelta y consciencia de clase. Barcelona: Crítica Grijalbo, 1984. p. 13-61.

- A miséria da teoria ou um planetário de erros: crítica ao pensamento de Althusser. Rio de Janeiro: Zahar, 1981. 


\section{Popular Education: a collec- tive project of Popular Social Movements}

\section{Abstract:}

This article analyzes popular education in rural areas, with a focus on education as conceived by collective political actors - populat social movements - to counter the "civilizing" model of the modern school. It seeks to unveil the contradictory concepts that impregnate the concepts and experiences of popular organizations as subjects of popular education. Modern bourgeois education is limited to processes in the schools, neglecting learning from experience, culture and work. In the same way that work is educational, participation in popular social movements is also educational considering its role in the formation of class and class identity. Popular education thus has a class character and it is this which distinguishes the abstract concept of modern education. The criticism of education limited to schools does not deny the importance of school institutions nor does it fail to recognize the right of the popular classes to education, which is universal. The paper reviews the concept of popular education, reviving its relationship with the world of labor, where social movements are constituted and which define them in their social and pedagogical practices.

Key words: Popular Education. Social and Education Movements. Labor and Education.

\section{Educación Popular: un proyec- to colectivo de los Movimien- tos Sociales Populares}

\section{Resumen:}

El presente artículo trata de la educación popular en relación al campo. Tiene como interés explicar la educación proyectada por los sujeto politicos colectivos de los movimientos sociales populares en contraposición al modelo civilizatorio de la escuela moderna, como también, desvendar el movimiento contradictorio que impregna los conceptos y las experiencias de las organizaciones populares como sujetos de la educación popular. La educación moderna producida por la burguesía está reducida a los procesos escolares, negando los aprendizajes de la experiencia, de la cultura y del trabajo. Del mismo modo que el trabajo es el principio educativo, el movimiento social popular es educador en cuanto formador de clase y de una identidad de clase. $\mathrm{La}$ educación popular tiene así un carácter de clase y es eso lo que distingue del concepto abstracto de educación moderna. La crítica a la educación reducida a la escuela no significa negar la institución escolar o dejar de reconocer el derecho de las clases populares a la educación, que es universal. Nuestra finalidad es buscar elementos para construir la concepción de educación popular recuperando su relación con el mundo del trabajo, donde se constituyen los movimientos sociales populares que se definen, en sus prácticas sociales y pedagógicas.

Palabras-clave: Educación popular. Movimientos sociales y educación. Trabajo y Educación. 


\section{Marlene Ribeiro}

Rua Dona Laura, $n^{2}$ 924, apto 201 - Bairro Rio Branco CEP: 90430-090 - Porto Alegre - RS

E-mail. maribe@adufrgs.ufrgs.br

Recebido em: 3/4/2008

Aprovado em: 15/7/2008 